\title{
Current research in embankment dam engineering at Imperial College London
}

Tom Shire MEng, MSc, DIC

PhD Research Student, Imperial College London, UK Loizos Pelecanos MEng

PhD Research Student, Imperial College London, UK
Han Bo BEng, MSC

PhD Research Student, Imperial College London, UK

Howard Taylor MEng, MSC, DIC

PhD Research Student, Imperial College London, UK

This paper gives a short introduction to two research streams in embankment dam engineering underway at Imperial College London. The first is the modelling of embankment dam behaviour during earthquakes and the second is an investigation into the susceptibility of granular filters to internal erosion. The research motivation, methods and expected outcomes of each stream are discussed.

\section{Introduction}

Imperial College has a strong tradition, spanning nearly six decades, of research into embankment dam behaviour, from Bishop's early work on the stability of embankment slopes (Bishop, 1955) to the post-failure analysis and redesign of Carsington dam (Potts et al., 1990; Skempton and Vaughan, 1993) and Vaughan's research into the 'perfect filter' (Vaughan and Soares, 1982), to more recent analysis and redesign of the main dam embankments at Empingham and at Abberton reservoir (Kovacevic et al., 2007, 2013).

Today, there are two research streams into embankment dam engineering underway in the Department of Civil and Environmental Engineering at Imperial College. In addition to traditional modelling of large-scale embankment dam problems, which is at present focused on their behaviour during earthquakes, investigations are also being made on the susceptibility of granular filters to internal erosion. This paper outlines the research motivation, methods and expected outcomes of each of these two research streams.

\section{Particle-scale analysis of granular filters}

Filters protecting the core against internal erosion are one of the most critical features in zoned embankment dams. Most embankment dams are constructed using granular filters of sand and gravel. Granular filters are required to be internally stable, meaning that the finer filter particles should not be able to be washed out from between the coarser filter particles (ICOLD, 1994). A feature of internally unstable soils which makes them particularly hazardous is that the finer particles can be eroded at very low hydraulic gradients (Skempton and Brogan, 1994).
Loss of these finer particles can lead to local changes in permeability, settlement and loss of freeboard, the appearance of sinkholes and potential dam failure. For example, the $71 \mathrm{~m}$ high Gouhou dam in western China failed on first filling owing to erosion of internally unstable shoulder material, causing 288 casualties (Zhang and Chen, 2006). Figure 1 shows the remnant of the failed dam.

Nowadays simple, conservative filter rules are used to ensure internal stability in new dams, as comprehensively described by the recent ICOLD Bulletin on Internal Erosion (ICOLD, 2013). However, many older dams were constructed before these rules were developed and a more precise set of tools is needed to assess the risks to these structures. To develop such tools it is first necessary to better understand what actually leads a material to be internally unstable.

One of the major obstacles to improving our understanding of internal instability is that mainstream experimental methods, such as permeameters, only allow external measurement of variables such as water pressures and the quantity of eroded material; what is happening in the filter must be deduced from these external observations. For a more scientific assessment of internal instability, two questions must be addressed, both of which require knowledge of the filter structure, as illustrated in Figure 2.

1. Are the finer filter particles free to be moved by seepage flows, or are they held in place by stresses from the coarser particles?

2. If free to move, can the finer particles fit through the pore network between the coarse, load-carrying 'skeleton'?

Two new techniques are employed in the attempt to answer these questions. These methods 'look inside' granular filters 
Dams and Reservoirs

Volume 23 Issue 1
Current research in

embankment dam engineering

at Imperial College London

Shire, Pelecanos, Bo and Taylor

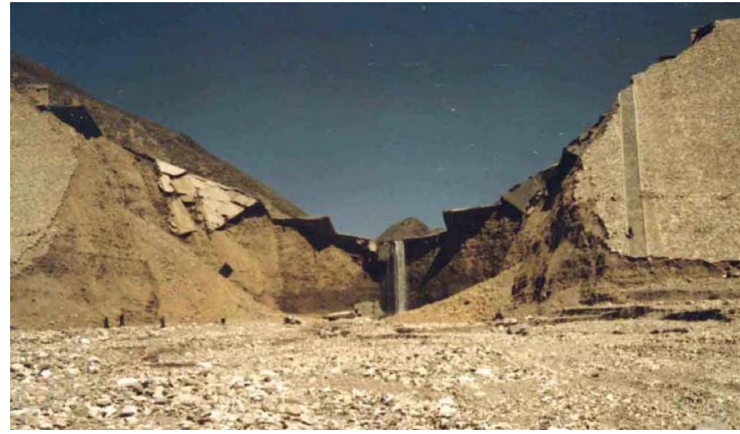

Figure 1. Gouhou dam failure, 1993 (Chang, 2012)

and directly measure the critical characteristics leading to internal instability. The first technique is the discrete element method (DEM), a type of numerical analysis, and the second is micro-computed tomography (micro-CT), an experimental method. Both these techniques operate at a 'particle-scale', meaning they generate data which can quantify features of individual filter particles.

\subsection{DEM}

Like a real soil mass, a DEM model is made up of individual particles which are in contact with one another. DEM models calculate the stresses and displacement of each particle, and hence the soil mass. Figure 3(a) shows a digital image of a DEM model.

DEM can be used to provide two data sets which are useful for assessing internal instability. The first is the geometry of the filter material: particle sizes, locations and which neighbouring particles are in contact with one another. From this information a way has been developed to measure the narrowest 'throats' within the network of pore space between the coarser particles, which control whether any finer particles can actually be eroded (Shire et al., 2013). Figure 3(b) shows a digital image

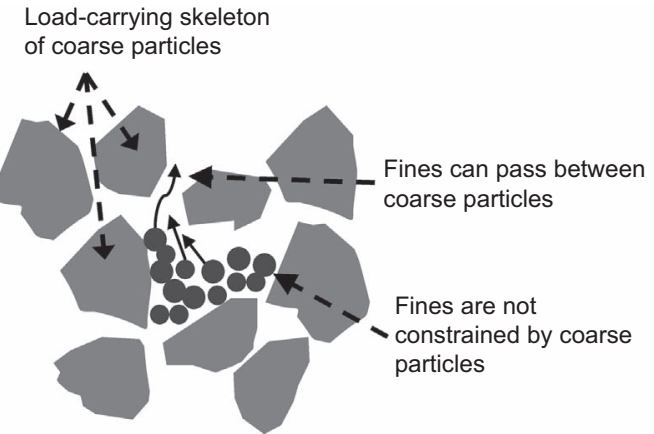

Figure 2. Schematic diagram of prerequisites of internal instability

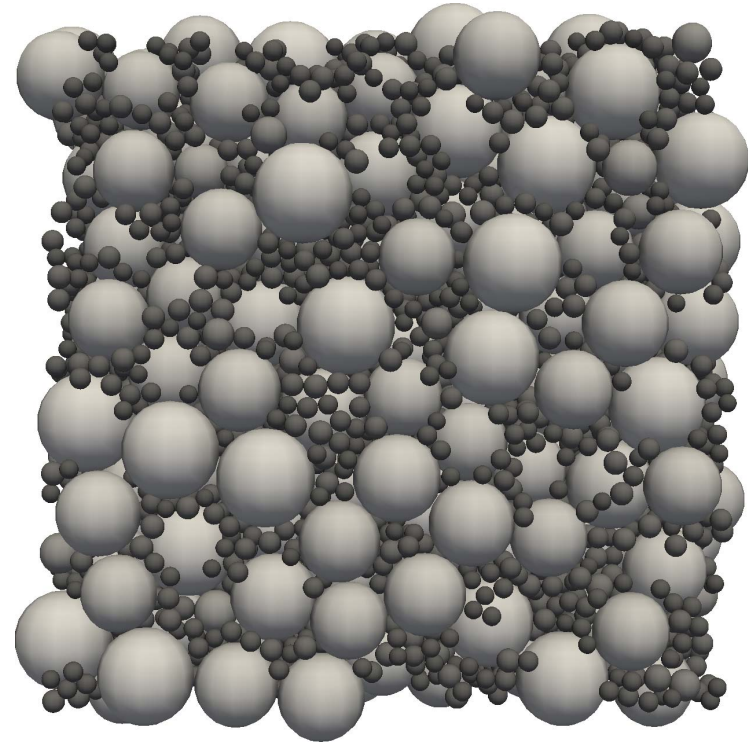

(a)

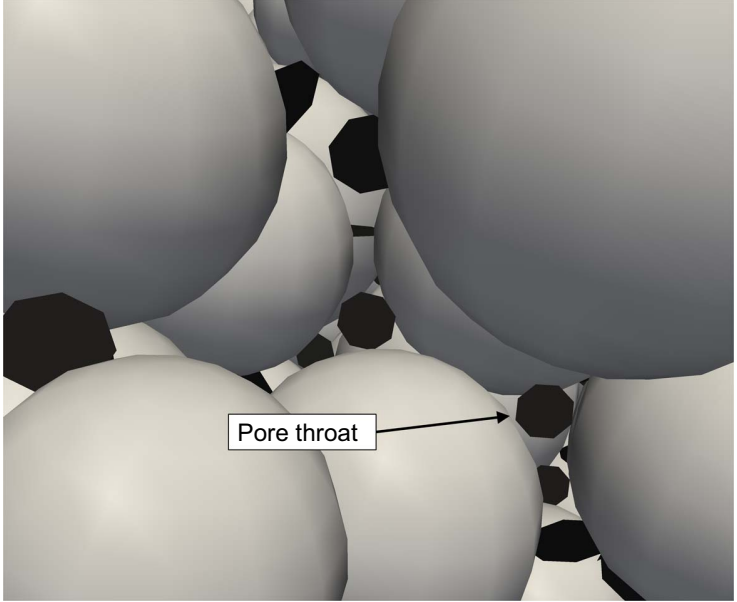

(b)

Figure 3. DEM images (a) internally unstable filter sample; (b) porethroat measured between DEM particles

of these pore-throats, which are shown as circles between solid particles.

The second data set is the stresses acting on each particle, which the DEM model calculates using simple equations based on Newton's laws. The particle stresses give a measure of how easily a particle can be moved by a seepage flow through the filter: if fine particles are only under a very low stress, they will be easily erodible (as long as they can also fit through the pore network).

\subsection{Micro-CT scanning}

A major drawback of the DEM is that it requires a very large computer capacity. In order to reduce the computational 
Dams and Reservoirs

Volume 23 Issue 1
Current research in

embankment dam engineering

at Imperial College London

Shire, Pelecanos, Bo and Taylor requirement, soil particles must be idealised as perfect spheres (even with spherical particles, large models can still take several weeks to produce).

Therefore micro-CT is also used, which provides a nondestructive way to take high-quality images of the internal structure of a real filter material. The micro-CT used here is essentially the same as X-ray CT (CAT) scans, which are commonly carried out in hospitals. A micro-CT scanner takes $\mathrm{X}$-rays images at many angles and combines the resulting twodimensional (2D) images to form an accurate three-dimensional (3D) image. As the images contrast materials of differing density, the boundary between filter particles and pore-space can be easily identified.

The major difference between medical CT and geosciences micro-CT is that, with no fears of giving the test subjects radiation poisoning, much higher radiation levels can be used. This gives a much better image resolution than is possible in medical applications. Typically, features which are just a fraction of a millimetre can be made out, compared to a few millimetres for medical applications. Figure 4 shows a microCT image of sand taken from Fonseca (2011). Information about the geometry of the sample can be retrieved from the 3D image, producing a similar data set to the DEM model: particle locations, sizes and contacts between neighbouring particles. However, a micro-CT image is unable to provide information about particle stresses.

\subsection{Research outcomes}

A drawback of existing filter rules is that they only take account of the particle size distribution (PSD) and they ignore the bulk material density (i.e. level of compaction), stress level and particle shape. DEM and micro-CT are currently being used to

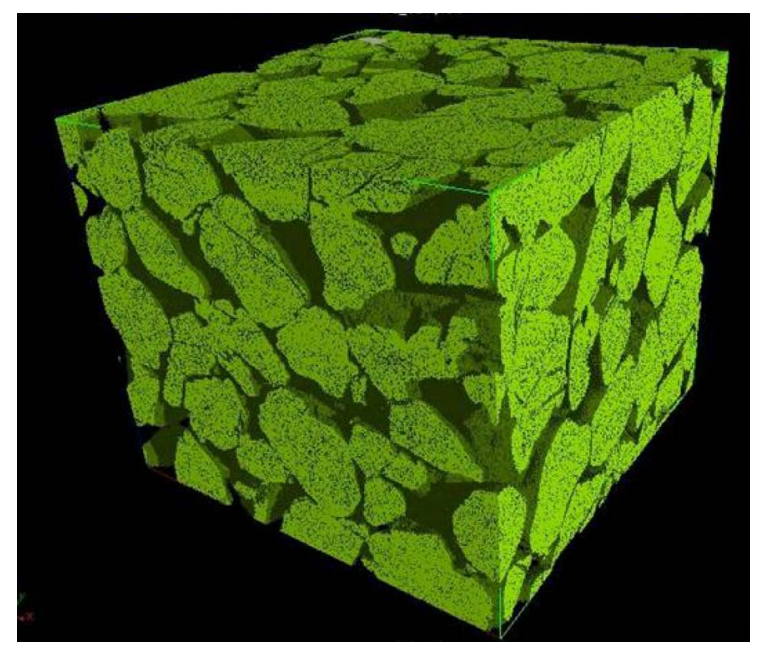

Figure 4. Micro-CT image of Reigate sand (Fonseca, 2011) analyse a range of different filter PSDs at a range of densities and overall stress levels. At first the generated pore-scale data are used to determine which existing filter rules have the best scientific basis and will therefore be the most accurate across a wide range of practical applications. Initial results have found good, but not perfect, correlations between a widely used filter rule and the DEM data (Shire and O'Sullivan, 2013). Next, micro-CT data, which are more realistic but harder to analyse, will be assessed in a similar way, allowing some of the idealisations of the DEM model to be identified.

Finally, the most important factors which are not considered in the existing filter rules will be identified, and ways will be proposed in which these can be accounted for. In order for the findings to be used practically with confidence, the results will be validated against high-quality laboratory testing using more established, mainstream methods, such as the permeameter tests of Moffat and Fannin (2011).

\section{Modelling the seismic behaviour of dams}

Earthquakes are one of the most dangerous and complex threats to embankment dams. They can cause slope failure or excessive deformations owing to high-intensity cyclic ground shaking, and large pore water pressures can be generated, leading to reduced earthfill strength and possible liquefaction. Earthquake loading on dams is extremely complicated: shear waves of many different amplitudes, frequencies and directions of propagation pass through the embankment and the soil responds to these in a highly non-linear manner. This makes it difficult to analyse how an embankment dam will respond during an earthquake of a given magnitude.

The finite-element method (FEM) is the most advanced analysis tool available for practical use in geotechnics. Used properly it can accurately model many aspects of embankment dam behaviour, for example hydraulic fracture of clay cores and progressive failure of embankment slopes (Dounias et al., 1996; Kovacevic et al., 2008). However, owing to its complex, dynamic nature, the modelling of seismic events with FEM is not well established.

Previous researchers at Imperial College have developed FEM models which are able to capture the seismic response of soils, for example Taborda (2011). These are now being applied to the elasto-plastic seismic analysis of dams and are being extended to include advanced features such as modelling the reservoir hydrodynamic pressures (Pelecanos et al., 2013) and the dynamic interaction between the reservoir and dam. Multiple shear-wave directions will be also allowed (instead of the standard assumption that all waves propagate horizontally).

The refined models are being implemented in Imperial College's bespoke geotechnical FEM code, ICFEP (Potts and 
Zdravković, 1999). The current authors are attempting to validate them against two well-documented case studies

La Villita dam, Mexico: a $60 \mathrm{~m}$ high zoned earthfill dam which has experienced deformation, but not failure, from six major earthquakes (Pelecanos et al., 2012)

- Yele dam, China: a $125 \mathrm{~m}$ high rockfill dam with an asphaltic concrete core, which is located about $250 \mathrm{~km}$ from the epicentre of the 2008 Wenchuan earthquake.

So far, significant progress has been made in back analysing the dams (reproducing the earthquake accelerations and displacements from field monitoring data). Once the FEM models have been validated and further refined, it will be possible to realistically model embankment dam response during test earthquakes, including predicting the most likely failure mechanisms for earthquakes of magnitudes well above those previously experienced by the dams. Such analysis will greatly aid risk assessment of existing dams as well as design and construction of new dams.

\section{Acknowledgements}

$\mathrm{Mr}$ Shire and Mr Taylor are working on the granular filter project with Dr Catherine O'Sullivan and Dr Way Way Sim. Both are funded by Engineering and Physical Sciences Research Council (EPSRC) Doctoral Training Grants. $\mathrm{Mr}$ Pelecanos and Mr Han are working on the seismic response project with Professor Lidija Zdravković and Dr Stavroula Kontoe. Mr Pelecanos is funded by EPSRC and Mr Han by the China Scholarship Council.

\section{REFERENCES}

Bishop AW (1955) The use of the slip circle in the stability analysis of slopes. Géotechnique 5(1): 7-17.

Chang DS (2012) Internal Erosion and Overtopping Erosion of Earth Dams and Landslide Dams. PhD thesis, Hong Kong University of Science and Technology.

Dounias GT, Potts DM and Vaughan PR (1996) Analysis of progressive failure and cracking in old British dams: Géotechnique 46(4): 621-640.

Fonseca J (2011) The Evolution of Morphology and Fabric of a Sand During Shearing. PhD Thesis, Imperial College London, UK.

ICOLD (International Commission on Large Dams) (1994) Bulletin No. 95: Embankment Dams - Filters and Drains. ICOLD, Paris, France.

ICOLD (2013) Bulletin on Internal Erosion of Dams, Dikes and their Foundations: Volume 1. ICOLD, Paris, France.

Kovacevic N, Potts DM and Vaughan PR (2008) Recent advances in the numerical modelling of embankment dams. Proceedings of the 15th Conference of the British Dam Society. Thomas Telford, London, UK, pp. 164-176. Kovacevic N, Higgins KG, Potts DM and Vaughan PR (2007)
Undrained behaviour of brecciated Upper Lias Clay at Empingham dam. Géotechnique 57(2): 181-195.

Kovacevic N, Hight DW, Potts DM and Carter IC (2013) Finite element analysis of the failure and reconstruction of the main dam embankment at Abberton reservoir, Essex, UK. Géotechnique 63(9): 753-767.

Moffat R and Fannin RJ (2011) A hydromechanical relation governing internal stability of cohesionless soil. Canadian Geotechnical Journal 48(3): 413-424.

Pelecanos L, Kontoe S and Zdravkovic L (2012) Static and dynamic analysis of La Villita Dam in Mexico. Proceedings of the 2nd International Conference on Performance-Based Design in Earthquake Geotechnical Engineering, pp. 10451056

Pelecanos L, Kontoe S and Zdravkovic L (2013) Numerical modelling of hydrodynamic pressures on dams. Computers and Geotechnics (accepted for publication).

Potts DM, Dounias GT and Vaughan PR (1990) Finite element analysis of progressive failure of Carsington embankment. Géotechnique 40(1): 79-101.

Potts DM and Zdravković L (1999) Finite Element Analysis in Geotechnical Engineering: Theory. Thomas Telford, London, UK.

Shire T and O'Sullivan C (2013) Micromechanical assessment of an internal stability criterion. Acta Geotechnica 8(1): 81-90.

Shire T, O'Sullivan C, Barreto D and Gaudray G (2013) Quantifying stress-induced anisotropy using inter-void constrictions. Géotechnique 63(1): 85-91.

Skempton AW and Brogan J (1994) Experiments on piping in sandy gravels. Géotechnique 44(3): 449-460.

Skempton AW and Vaughan PR (1993) The failure of Carsington dam. Géotechnique 43(1): 151-173.

Taborda D (2011) Development of Constitutive Models for Application in Soil Dynamics, $\mathrm{PhD}$ thesis, Imperial College London, UK.

Vaughan PR and Soares HF (1982) Design of filters for clay cores of dams. Journal of the Geotechnical Division ASCE 108(1): $17-32$.

Zhang LM and Chen Q (2006) Seepage failure mechanism of the Gouhou rockfill dam during reservoir water infiltration. Soils and Foundations 46(5): 557-568.

\section{WHAT DO YOU THINK?}

To discuss this paper, please email up to 500 words to the editor at editor@britishdams.org. Your contribution will be forwarded to the author(s) for a reply and, if considered appropriate by the editorial panel, will be published as discussion in a future issue of the journal. 